\title{
Abnormalities in the Distribution
}

\section{of Serum Immunoglobulin Concentrations}

in Juvenile Rheumatoid Arthritis

\author{
James T. Cassidy, Ross E. Petty, and Dontta B. Sullivan \\ From the Rackham Arthritis Research Unit, the Pediatric Arthritis Clinic and \\ Rehabilitation Service, and the Departments of Internal Medicine, and \\ Pediatrics and Communicable Diseases, The University of Michigan Medical School, \\ Ann Arbor, Michigan 48104
}

A в S T R A C T Concentrations of serum $\operatorname{IgG}, \operatorname{IgA}$, and IgM were determined in 200 patients with juvenile rheumatoid arthritis. The relative frequency distribution of IgG and IgM approached that of a log-normal curve; however, there was marked skewing of the distribution of the serum concentrations of $\operatorname{IgA}$. The prevalence of selective IgA deficiency was $4 \%$. In order to permit further intragroup comparisons, the serum immunoglobulin concentrations were standardized by comparison to a sex-age matched control group. By this process it was found that there was concordance of the serum levels of $\operatorname{IgG}$ with $\operatorname{IgA}$, and $\operatorname{IgG}$ with $\operatorname{IgM}$. The standardized concentrations of $\operatorname{IgA}$ and $\operatorname{IgM}$ were less in females than males. The aberration in distribution of serum IgA concentrations found in this study, and the relative inability of females to respond to their disease by increasing specific serum immunoglobulin levels, add further data supporting the concept of immunodeficiency in the pathogenesis of juvenile rheumatoid arthritis.

\section{INTRODUCTION}

Determination of serum immunoglobulin concentrations as part of the evaluation of a patient with connective tissue disease is of potential importance in furthering our understanding of the pathogenic processes involved in autoimmune and inflammatory reactions, and is of diagnostic value in detecting associated immunoglobulin deficiencies. In addition to the inflammatory joint disease found in patients with hypogammaglobulinemia (1-3), an association between juvenile rheumatoid arthritis (JRA) and selective IgA deficiency has been delineated (4-6).

Received for publication 3 January 1973 and in revised form 23 March 1973.
The significance of immunoglobulin measurements in a single individual expressed as serum concentrations in milligrams per milliliter has been difficult to assess because of biologic variables such as sex and age which affect their interpretation (7). A method for expressing immunoglobulin levels in relation to a population group stratified by sex and age has been developed in this laboratory in order to study discrete immunoglobulin responses in JRA. For ease of statistical analysis, a process of standardization has been used in which each immunoglobulin value is normalized by comparison to the control group. In this manner variations in immunoglobulin concentrations can be examined for previously unrecognized abnormalities and the relative range of comparative immunoglobulin values can be computed. In the present study data are developed which show that the relative frequency distribution of serum IgA concentrations is abnormal in patients with JRA, whereas the distributions of IgG and IgM are normal. In addition females with this disease exhibit a lesser degree of hypergammaglobulinemia in the $\operatorname{IgA}$ and $\operatorname{IgM}$ classes than males.

\section{METHODS}

Study groups. Sera from 200 patients with JRA (8) seen from 1961 to 1970 were analyzed. 144 were girls and 56 were boys. Active disease was present in $91 \%$. The patients ranged in age from one to $21 \mathrm{yr}$ (mean $10.1 \mathrm{yr}$ ) and age of onset of disease was 6 mo to $14 \mathrm{yr}$ (mean 5.8 yr). The first serum drawn on each individual was analyzed. Sera were also obtained for a disease comparison group from 263 children hospitalized with a variety of nonconnective tissue diseases. All sera not assayed immediately were frozen at $-70^{\circ} \mathrm{C}$.

Type of onset of disease (9) and functional class (10) were determined in the patients with JRA. Rheumatoid factors were assayed by a latex fixation tube dilution 
method (9) and antinuclear antibodies by an immunofluorescent technique (11).

Preparation of purificd immunoglobulins and antisera. IgG was prepared from Cohn fraction II $^{1}$ by DEAE-cellulose ${ }^{2}$ chromatography with $0.0175 \mathrm{M}$ phosphate buffer, $\mathrm{pH}$ 6.3 (12). IgA was prepared from myeloma sera by starch block electrophoresis in $0.075 \mathrm{M}$ barbital buffer, $\mathrm{pH}$ 8.6, (13) and Sephadex G-200 ${ }^{3}$ filtration with $1 \mathrm{M} \mathrm{NaCl}$ in 0.1 Tris- $\mathrm{HCl}$ buffer $\mathrm{pH} 8.2$ (14). IgM was isolated from macroglobulinemic sera by plasmapheresis, euglobulin precipitation, and Sephadex G-200 filtration. Light chains were isolated from urines of patients with myeloma by precipitation with $60 \%$ ammonium sulfate at $4^{\circ} \mathrm{C}$ followed by gel permeation chromatography on Sephadex G-100. The specificity of the isolated immunoglobulins was monitored by double diffusion in gel (15) and by immunoelectrophoresis (16) against antisera to each of the immunoglobulins and to whole serum. Antisera prepared in rabbits with specific immunoglobulins emulsified in Freund's complete adjuvant ${ }^{4}$ were cross-adsorbed with purified immunoglobulins and light chains.

Preparation of standard sera. The purified immunoglobulins were assayed for protein nitrogen by a micro-Kjeldahl procedure (17), and approximate Svedberg constants were determined by analytical ultracentrifugation in $0.02 \mathrm{M}$ phosphate, $0.12 \mathrm{M} \mathrm{NaCl}$, pH 7.2, to be $7 s^{0}{ }_{20, w}$ for IgG and $\operatorname{IgA}$, and $19 s^{0}{ }_{20, w}$ for $\operatorname{IgM}$ (18). A set of working standards consisted of four dilutions of serum from a healthy donor stored in aliquots at $-70^{\circ} \mathrm{C}$. Immunoglobulin concentrations in these standards were determined by comparison to the purified immunoglobulin standards and to International Reference Preparation 67/95 (19). International units per milligram of protein were computed for $\operatorname{IgG}$ as $10.4, \operatorname{IgA} 56.4$, and $\operatorname{IgM} 12.2$.

Quantitation of Immunoglobulins in test sera. Immunoassay was performed by a radial diffusion method $(20,21)$ iil $0.8 \%$ Ionagar No. $2^{5}$ in Tris- $\mathrm{HCl}$ buffer, ionic strength $0.1, \mathrm{pH}$ 7.2. Four dilutions of the standard serum were included on each test plate. After incubation for $18-22 \mathrm{~h}$ at $4^{\circ} \mathrm{C}$, the perpendicular diameters of the precipitin rings were measured on a micrometer stage and averaged. The concentration of immunoglobulin was read from a curve constructed from the standards and was linear for the following ranges of concentrations: IgG 3 to $16 \mathrm{mg} / \mathrm{ml}, \operatorname{IgA}$ 0.5 to $2.5 \mathrm{mg} / \mathrm{ml}$, and $\operatorname{IgM} 0.3$ to $2.0 \mathrm{mg} / \mathrm{ml}$. Sera with low immunoglobulin content were reassayed using diluted standards by the electroimmunodiffusion method of Laurell (22). The limit of detectability for $\operatorname{IgA}$ by double diffusion in agar with the anti-IgA antiserum used in this study was $0.005 \mathrm{mg} / \mathrm{ml}$. Sera with immunoglobulin concentrations in excess of the highest values on a standard curve were diluted so that concentrations could be evaluated on the ratio measurement scale.

Reproducibility of radial immunodiffusion. The coefficient of variation for repeated measurements of a standard serum during a $2 \mathrm{yr}$ period was computed with the formula $100 t_{n-1}(\mathrm{SD} / \mathrm{mean})$ in order to obtain the $95 \%$ confidence limits for each assay. These values were $\pm 17 \%$ for IgG, $\pm 20 \%$ for $\operatorname{IgA}$, and $\pm 27 \%$ for $\operatorname{IgM}$.

Standardization of immunoglobulin concentrations. Normal values for serum immunoglobulin concentrations for

${ }^{1}$ American Red Cross, Bethesda, Md.

Schleicher \& Schuell, Inc., Keene, N. H.

${ }^{3}$ Pharmacia, Uppsala, Sweden.

- Difco Laboratories, Detroit, Mich.

${ }^{5}$ Consolidated Laboratories, Inc., Chicago Heights, Ill. the sex-age ranges present in this study were established with 520 sera from a community health study. These sera were segregated by sex into 5-yr age groups, and means and standard deviations for the immunoglobulins were determined on $\log _{\text {e }}$ transformed data which represented the central $95 \%$ of the original computation. For the group at $10 \mathrm{yr}$, which was the mean age of the patients in this study, these values in milligrams per milliliter and the slopes of the respective regression lines in $\log _{e}$ units per year of age were: males-IgG $10.41,2.6 \pm 0.8 \times 10^{-3}$, IgA $1.16,1.3 \pm 0.1$ $\times 10^{-2}$, and $\operatorname{IgM} 0.77,0.16 \pm 1.6 \times 10^{-3}$; females-IgG 11.13 , $1.3 \pm 0.8 \times 10^{-3}, \operatorname{IgA} 1.15,1.0 \pm 0.1 \times 10^{-2}$, and $\operatorname{IgM} 1.06,-1.5$ $\pm 1.5 \times 10^{-3}$

Immunoglobulin concentrations in milligrams per milliliter in an unselected population are not homoscedastic (7); however, logarithmic derivatives yield a normal distribution. $\log _{e}$ transformations were therefore performed on the immunoglobulin concentrations of the individuals with JRA before standardization, as this process depends upon the use of confidence intervals symmetrically placed about the mean. Standardization permits subsequent use of statistical procedures which employ parametric concepts and allows expression of a sex-age corrected value which is an accurate indication of an immunoglobulin's concentration in relation to the spectrum of values seen in a normal population. In the process of standardization the appropriate sex-age mean for each immunoglobulin in the control population is subtracted from the patient's respective immunoglobulin concentration, and the result divided by the corresponding standard deviation. For example, a standardized value of 2.00 indicates that the measured serum concentration for that immunoglobulin is two standard deviations greater than the population sex-age mean.

Statistical methods. Parametric tests included Student's $t$ test, analysis of variance and covariance, and the Pearson correlation (23). The statistical programs of the Michigan Terminal System on an IBM $360 / 67$ duplex computer were used (24) and a $P$ value equal to or less than 0.05 was accepted as significant.

\section{RESULTS}

Extent of hypergammaglobulinemia in patients with $J R A$ as a function of sex. Immunoglobulin values before and after standardization are shown in Table I. The intensity of hypergammaglobulinemia was related to sex. Males developed a greater increase in serum concentrations of $\operatorname{IgA}(P<0.003)$ and $\operatorname{IgM}(P<0.01)$ in response to their disease than females. Serum levels of IgG were comparable in both sexes. This observation was not related to type of onset of disease or differences in medical therapy between the two groups. Although the range of measured values was considerable, hypergammaglobulinemia was not age related. Correlation coefficients computed for the standardized immunoglobulin values indicated that an appropriate correction for age had obtained $(r=-0.04$ to -0.07$)$.

Estimate of concordance of serum immunoglobulin concentrations. Correlations on interrelationships of the standardized serum immunoglobulin concentrations were examined. Concordance was demonstrated for IgG with $\operatorname{IgA}(P<0.01)$, and for IgG with $\operatorname{IgM}(P<0.001)$. 
TABLE I

Concentrations of Serum Immunoglobulins

\begin{tabular}{llrrrrrr}
\hline Class & & Mean & SD & Range & Mean* & SD* & Range* \\
\hline \multirow{5}{*}{ IgG } & Total group & 15.80 & 8.05 & $5.70-58.00$ & 2.00 & 2.76 & $-1.19-13.97$ \\
& Females & 15.29 & 8.55 & $5.70-58.00$ & 2.08 & 2.97 & $-1.19-13.97$ \\
& Males & 14.88 & 6.64 & $5.70-39.00$ & 1.80 & 2.13 & $-0.98-9.41$ \\
IgA & Total group & 1.92 & 1.40 & $0-8.20$ & 1.61 & 2.43 & $-2.60-12.34$ \\
& Females & 1.72 & 1.31 & $0-7.00$ & 1.29 & 2.26 & $-2.60-8.95$ \\
& Males & 2.43 & 1.51 & $0-8.20$ & 2.45 & 2.68 & $-1.94-12.34$ \\
IgM & Total group & 1.92 & 1.58 & $0.32-13.23$ & 2.24 & 3.11 & $-1.22-23.40$ \\
& Females & 2.05 & 1.70 & $0.32-13.23$ & 1.93 & 2.67 & $-1.22-15.71$ \\
& Males & 1.61 & 1.17 & $0.48-7.70$ & 3.04 & 3.93 & $-0.73-23.40$ \\
& & & & & & & \\
\hline
\end{tabular}

* Standarized values.

A partial correlation coefficient indicated that any relationship between $\operatorname{IgA}$ and $\operatorname{IgM}$ was probably based upon an interdependence with IgG.

Relative frequency distributions of serum immunoglobulin concentrations. Frequency distributions of the loge immunoglobulin concentrations are shown in Figs. 1-3. Cumulative distributions for each immunoglobulin on a normal probability scale are shown in the figure inserts. Divergence from linearity (dotted lines) in this probit analysis reflects deviation from a normal distribution of values (25). The frequency plot for IgG approached a normal distribution which was broad-based and skewed slightly to the higher values. Serum concentrations of IgM closely reflected a normal distribution. The cumulative plots for IgG and IgM concentrations (Figs. 1 and 3 ) were probably linear and represented in each case a single population.

The pattern of serum $\operatorname{IgA}$ concentrations was more complex with marked skewing, especially at the lower end of the concentration scale which included eight individuals with undetectable IgA. Probit transformation of these data (Fig. 2) indicated marked deviation from a normal distribution. This observation was not entirely accounted for by the group with selective IgA deficiency since nonlinearity in the lower values persisted when these eight individuals were excluded from the computation.

Selective IgA deficiency in children with JRA and in the comparison groups. Table II summarizes pertinent clinical data on the eight children with selective $\operatorname{IgA}$ deficiency and JRA. There were no children with undetectable $\operatorname{IgA}$ in the group of hospitalized children with nonconnective tissue diseases, nor in the group used to normalize the immunoglobulin values.

\section{DISCUSSION}

Recent studies have found elevated serum immunoglobulins in a significant but highly variable proportion of pa- tients with JRA $(26,27)$ but no direct comparison has been made to adequate sex-age matched control groups. Thus, while studies have demonstrated hypergammaglobulinemia in JRA, the degree and statistical significance of this finding remained unknown.

In the present investigation we sought to verify aberrations in serum immunoglobulin concentrations in JRA and to provide statistically meaningful data based on comparison with a sex-age matched control group. To this end, data have been converted to standardized values which, expressed in terms that indicate the degree of deviation from a matched control mean, permit valid intragroup comparisons. Elevation of IgM concentrations was greatest and showed the greatest range of variation. That this elevation was less in females than in males is indicated by the lower standardized value in females. The increase in serum IgA levels was less by comparison, but there too there was a discrepancy between the sexes with the mean standardized value for females being less than

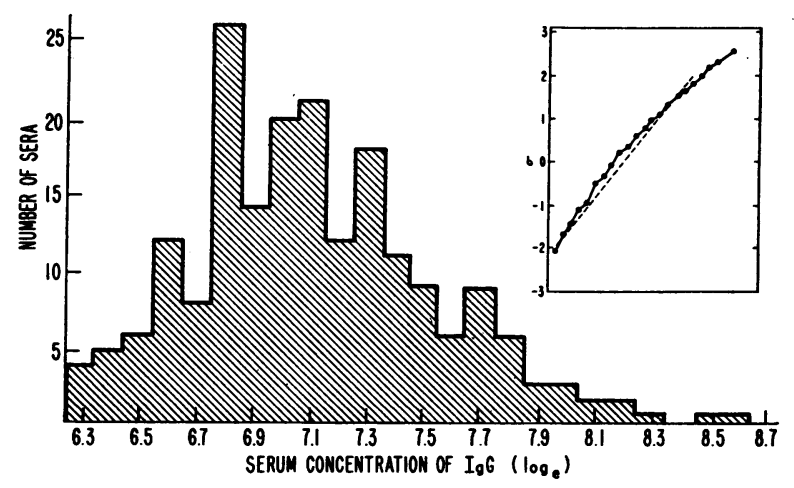

FIGURE 1 Relative frequency distribution of serum concentrations of $\mathrm{IgG}$ plotted as natural logarithms against number of sera. Cumulative distribution on a normal probability scale in the insert; dotted line is computed from $\pm 1.96 \mathrm{SD}$ of the data (95\% confidence limits). 


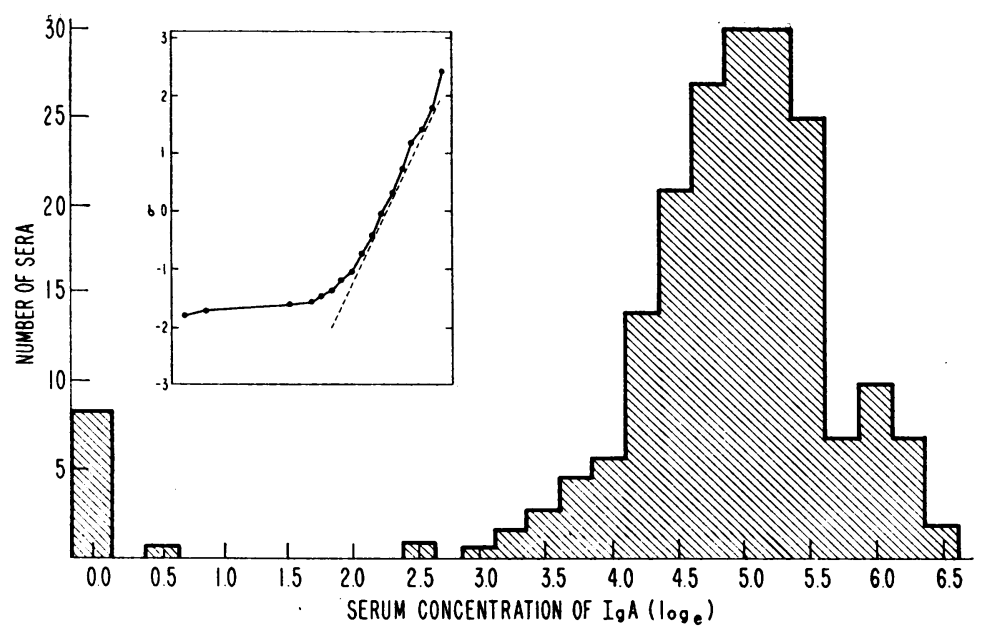

FIGURE 2 Relative frequency distribution of serum concentrations of IgA plotted as natural logarithms against number of sera. One was added to all values before logarithmic transformation in order to include the 0 concentrations. Eight patients with undetectable IgA were essentially beyond the defined limits of the abscissa on a logarithmic scale; therefore the indicated scale distance is only relative. Cumulative distribution on a normal probability scale in the insert; dotted line is computed from $\pm 1.96 \mathrm{SD}$ of the data with the cases of 0 concentration omitted.

that for males. These observations have been interpreted as representing a relative deficiency of immunoglobulin class response in females and may find significance in the fact that JRA is at least twice as common in girls as in boys. In individual patients in this study there was a marked concordant relationship between the concen-

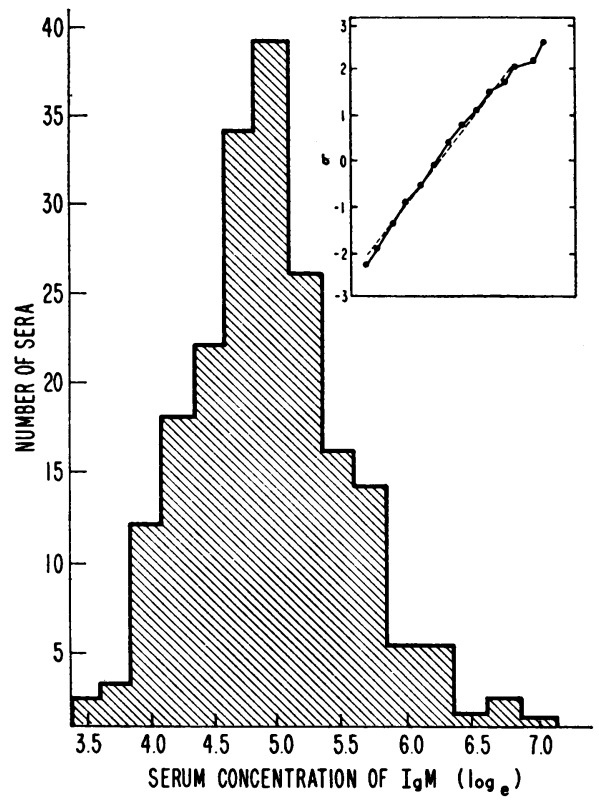

FIGURE 3 Relative frequency distribution of serum concentrations of $\operatorname{IgM}$ plotted as natural logarithms against number of sera. Cumulative distribution on a normal probability scale in the insert; dotted line is computed from $\pm 1.96 \mathrm{SD}$ of the data. trations of IgG and IgM, and a lesser but still significant dependence between IgG and IgA. Observations made in the present study must be tempered by the fact that serum immunoglobulins were measured at a single interval of time. Assays of sequential sera have been performed, however, on patients with undetectable $\mathrm{IgA}$ in our clinic, and this deficiency has been a consistent defect with one exception, a girl who had reversal of her immunodeficiency after plasma transfusions (28).

The pathologic significance of the diffuse hypergammaglobulinemia seen in patients with JRA, or its relationship to sex, is not clear. It may reflect a specific or a nonspecific response to antigenic stimuli or inflammation. Serum immunoglobulins in an individual patient reflect a dynamic equilibrium of synthesis, catabolism, and distribution within the vascular and extravascular compartments (29). Increases in both synthetic and catabolic rates of IgG have been demonstrated in patients with rheumatoid arthritis (30). In mice it has been shown that sex influences gamma globulin metabolism (31). Female mice of the A strain displayed discontinuous half-life distributions of $\boldsymbol{\gamma}$ G-globulin, whereas males showed a more symmetrical curve. In normal human females serum $\operatorname{IgM}$ concentrations are higher throughout the age span than in males (32).

Previous reports of serum immunoglobulin concentrations in the general population have indicated that they are log-normally distributed (7). In the present study in JRA, values for IgG and IgM were distributed $\log$ normally, while those for $\operatorname{IgA}$ were not. The significance of the occurrence in JRA of a group with selective $\operatorname{IgA}$ 
TABLE II

Clinical Data on Eight Patients with Selective IgA Deficiency and Juvenile Rheumatoid Arthritis

\begin{tabular}{lcccccccc}
\hline Sex & M & F & F & F & F & F & F & M \\
Age of onset (yr) & 8 & 7 & 9 & 12 & 9 & 7 & 5 & 1 \\
Duration of disease (yr) & 4 & 8 & 7 & 1 & 1 & 1 & 2 & 4 \\
Type of onset* & M & M & P & P & M & P & P & M \\
Functional class & II & II & II & III & II & III & II & II \\
Recurrent infections & - & - & - & - & - & + & - & - \\
Rheumatoid factors & - & - & - & - & - & - & - & - \\
Antinuclear antibodies & - & - & + & + & + & + & - & - \\
Serum IgG concentration & 2.28 & 0.70 & 0.52 & 2.66 & 1.87 & 0.52 & 13.8 & 1.08 \\
Serum IgM concentration & -0.45 & -0.90 & 0.57 & 2.90 & 2.10 & 8.98 & 1.12 & 2.40 \\
\hline
\end{tabular}

* Type of onset of disease is M, monarticular or oligoarticular, and P, polyarticular.

† Standardized values.

deficiency is enhanced by the tendency of the distribution of serum IgA concentrations to merge into it with partial deficiencies. It is unlikely that any of the individuals with selective IgA deficiency, which has been defined as undetectable serum $\operatorname{IgA}$ by the cited immunologic assays, have no IgA. In support of this hypothesis Grey, Rabellino, and Pirofsky have demonstrated IgA antigenic determinants on the surface of lymphocytes from patients with IgA deficiency (33).

Selective IgA deficiency is the most common humoral immunodeficiency with a frequency of $0.14 \%$ in adults (34). IgA deficiency has been reported in children with ataxia telangiectasia (35), in families of patients with hypogammaglobulinemia (36), in systemic lupus erythematosus (37), in steatorrhea (38), and in individuals with recurrent sinopulmonary infections $(39,40)$. IgA deficiency has also been reported in "normal" adult males (41).

Selective IgA deficiency might be secondary to the presence of anti- $\operatorname{IgA}$ antibodies. These anti-globulins have been described in some patients with ataxia telangiectasia who have increased immune elimination of exogenous IgA (42). It is also possible that transplacental passage of antibodies directed against lymphoid precursor cells destined to synthesize IgA might block their differentiation in the fetus. Dray has shown in rabbits that maternal isoantibodies to allotypic specificities of gamma globulin may interfere with the ability of the progeny to exhibit the corresponding allotype in serum (43). Kincade, Lawton, Bockman, and Cooper found that anti-IgM antibody injected into the chick embryo prevented development of both IgM and IgG producing cells and led to suppression of synthesis of these immunoglobulins after bursectomy (44). The report of Fudenberg and Fudenberg suggested that maternal 7S agglutinins directed against determinants in fetal gamma globulins might be important in the etiology of transient hypogammaglobulinemia of infancy (45).

The pathologic significance of the selective $\operatorname{IgA}$ deficiency seen in JRA is basically unknown. It was found in $4 \%$ of the patients in the present study. Other investigators have cited the frequency of IgA deficiency in JRA as $2-9 \%(5,26,46)$. As a form of immunodeficiency, this defect may be associated with impaired immunologic surveillance. In contrast to diffuse hypergammaglobulinemia, IgA deficiency may thus be more intimately related to pathogenesis as a reflection of a more profound but as yet unidentified immunologic disturbance involving the cellular immune system (46).

\section{ACKNOWLEDGMENTS}

The authors thank Ann Burt, M. T., for expert technical assistance, Janice Iravani, B.S., for statistical programming, Dr. Emil Jebe for suggestions on initial analysis, and Dr. Richard Cornell, Professor of Biostatistics, for continuing advice and counsel.

This work was supported by a grant from the Michigan Chapter of the Arthritis Foundation and a Rackham Facuity Grant. The Rackham Arthritis Research Unit is supported in part by a grant from the Horace H. Rackham School of Graduate Studies. The biostatistical services were supported by the University of Michigan Medical School Fund for Computing.

\section{REFERENCES}

1. Janeway, C. A., D. Gitlin, J. M. Craig, and D. S. Grice. 1956. "Collagen disease" in patients with congenital agammaglobulinemia. Trans. Assoc. Am. Physicians Phila. 69: 93.

2. Good, R. A., J. Rötstein, and W. F. Mazzitello. 1957. The simultaneous occurrence of rheumatoid arthritis and agammaglobulinemia. J. Lab. Clin. Med. 49: 343.

3. Lawrence, J. S. 1972. Rheumatic disease in hypogammaglobulinaemia patients and their relatives. In Hypogammaglobulinaemia in the United Kingdom. M. R. C. Working Party on Hypogammaglobulinaemia. Her Majesty's Stationery Office, London. 35.

4. Cassidy, J. T., A. Burt, D. B. Sullivan, and D. G. Dickinson. 1966. Changes in the serum immunoglobulins in juvenile rheumatoid arthritis. Arthritis Rheum. 9: 850. (Abstr.)

5. Huntley, C. C., D. P. Thorpe, A. D. Lyerly, and W. M. Kelsey. 1967. Rheumatoid arthritis with IgA deficiency. Am. J. Dis. Child. 113: 411.

6. Cassidy, J. T., and A. Burt. 1968. Selective hypogammaglobulinemia in rheumatoid arthritis. Univ. Mich. Med. Cent. J. $34: 241$. 
7. Buckley, C. E., III, and F. C. Dorsey. 1970. The effect of aging on human serum immunoglobulin concentrations. J. Immunol. 105: 964.

8. Brewer, E. H., J. Bass, J. T. Cassidy, B. S. Duran, C. W. Fink, J. C. Jacobs, M. Markowitz, W. E. Reynolds, J. Schaller, J. S. Stillman, and S. L. Wallace. 1973. Criteria for the classification of juvenile rheumatoid arthritis. Bull. Rheum. Dis. 23: 712.

9. Cassidy, J. T., and H. A. Valkenburg. 1967. A five year prospective study of rheumatoid factor tests in juvenile rheumatoid arthritis. Arthritis Rheum. 10: 83.

10. Steinbrocker, O., C. H. Traeger, and R. C. Batterman. 1949. Therapeutic criteria in rheumatoid arthritis. $J$. Am. Med. Assoc. 140: 659.

11. Petty. R. E., J. T. Cassidy, and D. B. Sullivan. 1973. Clinical correlates of antinuclear antibodies in juvenile rheumatoid arthritis. J. Pediatr. In press.

12. Peterson, E. A., and H. A. Sober. 1962. Column chromatography of proteins: substituted celluloses. Methods Enzymol. 5: 3 .

13. Kunkel, H. G., and R. J. Slater. 1952. Zone electrophoresis in a starch supporting medium. Proc. Soc. Exp. Biol. Med. $80: 42$.

14. Flodin, R., and J. Killander. 1962. Fractionation of human-serum proteins by gel filtration. Biochim Biophys. Acta. $63: 403$.

15. Ouchterlony, O. 1949. Antigen-antibody reactions in gels. Acta Pathol. Microbiol. Scand. 26: 507.

16. Scheidegger, J. J. 1955. Une micro-méthode de l'immuno-électrophorèse. Int. Arch. Allergy Appl. Immunol. 7: 103.

17. Steyermark, A. 1961. Quantitative Organic Microanalysis. Academic Press, Inc., New York. 2nd edition. 205.

18. Svedberg, T., and K. O. Pedersen. 1940. The Ultracentrifuge. Oxford University Press, Inc., New York.

19. Rowe, D. S., S. G. Anderson, and B. Grab. 1970. A research standard for human serum immunoglobulins IgG, IgA and IgM. Bull. WHO. 42: 535.

20. Mancini, G., A. O. Carbonara, and J. F. Heremans. 1965. Immunochemical quantitation of antigens by single radial immunodiffusion. Immunochemistry. 2: 235.

21. Fahey, J. L., and E. M. McKelvey. 1965. Quantitative determination of serum immunoglobulins in antibodyagar plates. J. Immunol. $94: 84$.

22. Laurell, C.-B. 1966. Quantitative estimation of proteins by electrophoresis in agarose gel containing antibodies. Anal. Biochem. $15: 45$.

23. Dixon, W. J., and F. J. Massey, Jr. 1969. Introduction to Statistical Analysis. McGraw-Hill Book Co., New York. 3rd edition. 63, 116, 202.

24. Bartels, R. C. F., editor. 1971. The Michigan Terminal System. The University of Michigan Computing Center, Ann Arbor. 3rd edition.

25. Finney, D. J. 1971. Probit Analysis. University Printing House, Cambridge, England. 3rd edition. 8, 22.

26. Bluestone, R., L. S. Goldberg, R. M. Katz, J. M. Marchesano, and J. J. Calabro. 1970. Juvenile rheumatoid arthritis: a serologic survey of 200 consecutive patients. J. Pediatr. 77 : 98.

27. Houba, V., and R. Bardfeld. 1969. Serum immunoglobulins in juvenile rheumatoid arthritis. Ann. Rheum. Dis. 28: 55

28. Petty, R. E., J. T. Cassidy, and D. B. Sullivan. 1973. Reversal of selective IgA deficiency in a child with juvenile rheumatoid arthritis after plasma transfusions. Pediatrics. 51: 44
29. Waldman, T. A., W. Strober, and R. M. Blaese. 1971. Variations in the metabolism of immunoglobulins measured by turnover rates. In Immunoglobulins. E. Merler, editor, National Academy of Sciences, Washington. 33.

30. Andersen, S. B., and K. B. Jensen. 1965. Metabolism of $\gamma$ G-Globulin in collagen disease. Clin. Sci. 29: 533.

31. Watkins, J., D. E. H. Tee, J. J. Finn, and P. M. Johnson. 1968. Sex-linked factor influencing the catabolism of serum $\gamma \mathrm{G}$-globulins and transferrins in the mouse. Nature (Lond.). 219: 295.

32. Butterworth, M., B. McClellan, and M. Allansmith. 1967. Influence of sex on immunoglobulin levels. $\mathrm{Na}$ ture (Lond.). 214: 1224.

33. Grey, H. M., E. Rabellino, and B. Pirofsky. 1971. Immunoglobulins on the surface of lymphocytes. IV. Distribution in hypogammaglobulinemia, cellular immune deficiency, and chronic lymphatic leukemia. $J$. Clin. Invest. 50: 2368.

34. Bachmann, R. 1965. Studies on the serum $\gamma \mathrm{A}$-globulin level. III. The frequency of a- $\gamma \mathrm{A}-$ globulinemia. Scand. J. Clin. Lab. Invest. $17: 316$.

35. Peterson, R. D. A., W. D. Kelly, and R. A. Good. 1964. Ataxia-telangiectasia. Lancet. 1: 1189.

36. Fudenberg, H., J. L. German, III, and H. G. Kunkel. 1962. Occurrence of rheumatoid factor and other abnormalities in families of patients with agammaglobulinemia. Arthritis Rheum. 5: 565.

37. Bachmann, R., C.-B. Laurell, and E. Svenonius. 1965. Studies on the serum $\gamma 1 \mathrm{~A}$-globulin level. II. $\gamma 1 \mathrm{~A}$-deficiency in a case of systemic lupus erythematosus. Scand. J. Clin. Lab. Invest. $17: 46$.

38. Crabbé, P. A., and J. F. Heremans. 1967. Selective IgA deficiency with steatorrhoea. Am. J. Med. 42: 319.

39. West, C. D., R. Hong, and N. H. Holland. 1962. Immunoglobulin levels from the newborn period to adulthood and in immunoglobulin deficiency states. J. Clin. Invest. $41: 2054$.

40. Ammann, A. J., and R. Hong. 1971. Selective IgA deficiency: presentation of 30 cases and a review of the literature. Medicine (Baltimore). 50: 223.

41. Rockey, J. A., L. A. Hanson, J. F. Heremans, and H. G. Kunkel. 1964. Beta-2A-aglobulinemia in two healthy men. J. Lab. Clin. Med. 63: 205.

42. Strober, W., R. D. Wochner, M. H. Barlow, D. E. McFarlin, and T. A. Waldmann. 1968. Immunoglobulin metabolism in ataxia telangiectasia. J. Clin. Invest. 47: 1905.

43. Dray, S. 1962. Effect of maternal isoantibodies on the quantitative expression of two allelic genes controlling $\gamma$-globulin allotypic specificities. Nature (Lond.). 195: 677.

44. Kincade, P. W., A. R. Lawton, D. E. Bockman, and M. D. Cooper. 1970. Suppression of immunoglobulin $\mathrm{G}$ synthesis as a result of antibody-mediated suppression of immunoglobulin M synthesis in chickens. Proc. Natl. Acad. Sci. U. S. A. 67: 1918.

45. Fudenberg, H. H., and B. R. Fudenberg. 1964. Antibody to hereditary human gamma-globulin $(\mathrm{Gm})$ factor resulting from maternal-fetal incompatibility. Science (Wash. D. C.). 145: 170 .

46. Panush, R. S., N. E. Bianco, P. H. Schur, R. E. Rocklin, J. R. David, and J. S. Stillman. 1972. Juvenile rheumatoid arthritis. Cellular hypersensitivity and selective IgA deficiency. Clin. Exp. Immunol. 10: 103. 